\title{
The Postsecondary Enrollment of African American Men: Perceptions of Environmental Variables
}

\author{
David V. Tolliver, Jr. \\ Division of Student Success, Southwest Minnesota State University \\ IL 224D, Marshall, Minnesota 56258, United States

\begin{abstract}
Michael T. Miller (Corresponding author)
Department of Rehabilitation, Human Resources, and Communication Disorders, University of Arkansas
\end{abstract} \\ Fayetteville, Arkansas 72701, United States \\ G. David Gearhart \\ Department of Rehabilitation, Human Resources, and Communication Disorders, University \\ of Arkansas
}

Fayetteville, Arkansas 72701, United States

Received: Feb. 18, 2021 Accepted: Mar. 17, 2021 Online published: Apr. 9, 2021

doi:10.5296/jpag.v11i2.18311～URL: https://doi.org/10.5296/jpag.v11i2.18311

\begin{abstract}
Higher education has made progress in the enrollment of under-represented minorities, yet very notably, African American men continue to enroll in college at very low rates. The current study explores the factors that lead to the college enrollment of African American men, using the lived experiences of 8 undergraduates at mid-western universities. The study findings are consistent with the emerging theory of Community Expectancy, suggesting that many informal factors play important roles in encouraging the academic performance and ultimately the college enrollment of African American men.
\end{abstract}

Keywords: human capital, college access, community expectancy, family influence

\section{Introduction}

Race continues to be a significant social issue in the United States. Whether discussing 
political elections, buying patterns, or earning potential, an individual's racial identity has become one of the defining criteria for understanding societal behavior. In addition, recent and recurring social challenges that highlight violence against different racial identities, the topic can incite a tremendous emotional community response.

Within the spectrum of racial identity, the African American man is perhaps one of the most studied and least understood. Individuals who claim this racial identity are among the least likely to graduate from high school, attend and graduate from any postsecondary education, and are among the most likely to be incarcerated or unemployed (Browne \& Battle, 2018; Eckholm, 2006). Even as all racial identities are experiencing historically high enrollment in postsecondary education, African American men continue to lag in their enrollment (Snyder \& Dillow, 2011).

Postsecondary enrollment has been identified as having a positive impact on an individual. College graduates have not only higher lifelong earnings, but they are less likely to engage in unhealthy behaviors such as substance abuse, are less likely to be obese or have extreme health problems, are more likely to be engaged in their communities, vote, and report a higher level of satisfaction with their lives. The implication is that if African American men are not participating and graduating from college, they opportunities and choices are less likely to result in positive, meaningful lives that engage with their communities. Eckholm (2006) found that nearly three-fourths of African American men who did not go to college were unemployed.

The result of this problem is that there is an articulated and real need to understand how African American men get into and graduate from college. Browne and Battle (2018) identified a range of services that might assist students once in college, such as mentoring services, academic support services such as tutoring, and socialization programs that lead students to build and develop social support networks. However, as Causey, Livingston, and High (2015) noted, there is a need to understand the pre-college variables that can influence a student's postsecondary enrollment, particularly an individual's family.

A young adult considering post-secondary school options can be influenced by a wide-range of variables. The family plays an important role in helping the individual identify what is valued in life and society, but there are other variables that can situationally have as strong of, if not stronger, impact. These might include peer group, formal education bodies such as schools, neighbors, community members, and those involved with civic life. These associations have been described as 'community expectancy,' that is, the growing field theory that suggests that communities can exert expectations on their members (Derden \& Miller, 2014; Deggs \& Miller, 2011).

The purpose for conducting the study was to identify and describe the perceived and self-reported enabling factors that aided African American men in enrolling and graduating from college. The qualitative study was designed to specifically to tell the stories of undergraduates and what they perceived as meaningful to them throughout their decision-making process for attending college, and then the critical variables that they experienced in making their way through college. The results of the study can then lead to the 
possible creation of policies and practices that help improve the opportunities for African American men to attend college and benefit from the outcomes associated with higher education attainment.

\section{Background of the Study}

\subsection{African American Men in College}

The National Center for Education Statistics (2014) indicate that about a third of all African American men enroll in college (28.5\%), but that only $7.8 \%$ of adult African American men are college graduates. These college going students come from just over two-thirds of African American men who graduate from high school (Cook \& Cordova, 2007).

The decision to attend college has been described as being influenced by a wide variety of interactions and experiences. Participation in high school activities, for example, has been noted for broadening student thinking and helping the student understand or appreciate the idea of further education (Newton, \& Onésimo Sandoval, 2015). This involvement leading to an openness of thinking also includes participation in high school sports (Braddock \& Hua, 2006), as well as the academic-focus of the student's high school (Kim, Chatterjee, Young, \& Moon, 2017).

The decision to attend college, including either a community or a 4-year college, has also been correlated to parental education levels and expectations (Newton \& Onesimo Sandoval, 2015). These correlations typically suggest that the higher the parental education level, the more likely they are to support the child's desire and effort to enroll in postsecondary education. The higher education level has also been visible in the involvement of the parent in the child's education and life-decisions, including supporting academic achievement and finding help for academics if necessary (Teklessassie, Mallery, \& Choi, 2013).

Even with strong family and school support, some students struggle with the protocols of gaining admission to college and funding their educational experiences (Elliott \& Nam, 2012). Many institutions have attempted to target their enrollment support services particularly for African Americans, yet these programs are sporadic and often inconsistent in their effectiveness to reach under-represented populations, particularly those who are first-generation college students (Venezia \& Jaeger, 2013; Price \& Sheftall, 2015).

Once enrolled in college, African American men face a variety of challenges and barriers, both real and perceived. These roadblocks to graduation have been identified at both Historically Black Colleges and Universities (HBCUs) as well as Primarily White Institutions (PWIs), and include issues such as an inability to build cultural capital to support them during difficult personal and academic challenges (Tobolowsky, Outcalt, \& McDonough, 2005). Access to supportive academic services, financial aid counseling, and peer and faculty mentoring have all been identified as critical to the persistence and graduation of African American men (Warde, 2008). Their absence, however, has resulted in greater part-time enrollment, a greater likelihood of inconsistent enrollment, and a greater likelihood of dropping out (Ewert, 2010; Warde, 2008). 
Other elements that have been identified as positively influencing African American men graduating from college include strong family and community support networks (Scott, Taylor, \& Palmer, 2013), and on campus, responsive academic support services (Kim \& Hargrove, 2013). Brooms (2018) and Yosso (2005) both identified the importance of social and cultural capital for African American men for college completion. They noted that skill and intelligence were critical for academic performance, but that shortcomings could be remedied and students could work through difficult times if they had networks of support and encouragement that ultimately helped them strengthen their personal resiliency.

The research on the African American man attending college is complex, diverse, and offers no singular solution to improving attendance and graduation. The research does, however, stress the duality of supporting these students as they consider college as a postsecondary option, and then providing key supports to them while they are enrolled. Although in-college supports have been identified as critical, there is little consensus as to what these might include or how they might be structured, reinforcing the need for the current study to tell the stories of men who have been successful in their college experiences.

\subsection{Parent and Family Influence}

The family environment provides potentially the most intimate, consistent, and strongest pressure on an individual, particularly during early youth. There are, however, multiple definitions and perspectives as to what constitutes a family structure. For some, strong grandparent involvement is visible, in others, a single parent raises a child, and in others, aunts and uncles play important parental roles. These family structures have the potential to impact the development of a youth, often with varying outcomes. Ginther and Pollak (2004) found that traditional nuclear families with two parents were more likely to raise children who performed well academically and went to college then non-traditional family structures. Madyun and Lee (2010) found the same results as evidenced by higher secondary school grade point averages for students from traditional family backgrounds. DeBell (2008) reported that $69 \%$ of African American men live in fatherless homes.

Part of the difficulty of a single parent family has to do with the availability of the parent, balancing work, household management, and parenting, typically tasks and responsibilities that can be shared in at two-parent home (Hines \& Holcomb-McCoy, 2013). Additionally, the ability to share responsibilities in parenting can result in different parenting styles. Turner, Chandler, and Heffer (2009), for example, found that parenting that includes warmth, supportiveness, and encourages motivation can significantly predict better academic performance in school. Conversely, punitive-based parenting has been found to result in lower academic performance (Robinson \& Harris, 2013), although Hines and Holcomb-McCoy (2013) could not find any predictive correlations between parenting style and academic performance.

A wide variety of parenting-related issues have also been found to impact a student's perceptions of the value of education and academic achievement. Some of these align parent and student values of education (Purtell \& McLoyd, 2013), especially for African American men who are apt to be more greatly influenced by their parents' attitudes toward the value of 
educational attainment than others (Zhang, Haddad, Torres, \& Chen, 2011). African American men were also found to be highly influenced by the behaviors and messages of their parents, especially in the areas of academic effort, achievement, future educational goals (Kerpelman, Eryigit, \& Stephens, 2008).

The particular challenge for African American men, then, is their reliance on their family structure. If the family structure is supportive of doing well in school, these men do well. Coming primarily from fatherless homes, however, they face the difficulties of being in single-parent homes where the value of education may be repressed in favor of work and making financial contributions to the family.

\subsection{Community Expectancy}

Identity formation has been linked to multiple variables and different life stages have been reported to be susceptible to different types of pressures and influences. Notably studied by psychologists such as Erikson $(1950 ; 1968 ; 1982)$, as an individual lives and ages, different stimuli interact with the individual causing responses, and some of these responses have a larger impact on who that individual becomes. The concept of community expectancy is particularly focused on individual identity formation during adolescence to early-adulthood, a time range that Erikson (1968) referenced as Identity versus Role Confusion (Sokol, 2009). In this age range, adolescents question themselves, who they are, and who they are becoming as they move closer to the adults who they will become.

Community expectancy broadly proposes that individuals are influenced not just by their family, which is indeed a powerful factor in a person's development (Bourdieu; 1986; Putnam, 2000), but by the various human elements that comprise a community (Deggs \& Miller, 2011A). The title of the emerging field theory references these community elements, and suggests that combined, they can exert an expectation on an individual (Miller \& Tuttle, 2006).

Community expectancy typically involves five elements of influencers, including formal education bodies, civic agencies, informal associations, religious affiliations, and home life (Deggs \& Miller, 2011A; 2011B). As an individual lives in society, these influencers can touch and challenge the worldview and expectations of an individual, resulting in such decisions and perceptions as attending postsecondary education or making determinations about appropriate roles in society (Derden, 2011; Derden \& Miller, 2014). Examples of influencing identity formation might include particularly stringent religious adherence which does not allow for questioning authority, strong formal educational environments which promote attending postsecondary education, and largely educated or uneducated local workforces that either value or do not value furthering education.

Community expectancy is based largely on the notion of cultural and human capital as studied and reported by Bourdieu (1986) and Winkle-Wagner (2010). Merolla and Jackson (2014) in particular, along with Lareau and Horvat (1999) related the importance of cultural capital activation on the decision-making process of attending formal education. Calarco (2011) similarly found that cultural capital also played a key role in an individual's decision 
to ask and seek help in both education and life planning.

The current study acknowledges the importance of capital activation within the framework of community expectancy, suggesting that African American men form their attitudes, beliefs, and perceptions about themselves and their future not just from immediate family members or school, but from the community around them. Therefore, discussions about making postsecondary decisions must incorporate this worldview of community expectation.

\section{Method}

As the purpose of the study was to identify and describe, a qualitative methodology was identified as the most appropriate data collection and analysis framework. As Creswell and Poth (2018) noted, this type of research method is most appropriate in developing a detailed understanding of an issue or problem. Within the qualitative framework, phenomenology was identified as the most appropriate response, as it allows the researcher to access the world of the subject through ordinary experiences (van Manen, 2014), and as Creswell and Poth (2018) wrote, the process can "describe the essence of a lived experience" (p. 81).

Within the phenomenological category, the transcendental phenomenological approach was selected to guide the interview process. This approach stresses a systematic approach to data collection along with a refrain from value judgements. In particular, as Moustakas (1994) stressed, the process requires the researcher to set aside prejudices, egos, values, or biases.

Data reliability and trustworthiness were aided by transcribing each interview and then providing the transcript of the interview back to the participant to review for accuracy and intentionality. Researcher field notes and journaling provided a triangulation of data and interpretation, and an independent third-party scholar was provided all data and coded responses and identified themes. This analysis was then compared to those codes and themes identified by the researcher, thus allowing for a verified identification findings.

Data for the study were collected from 8 African American men who were currently enrolled as undergraduate students in good academic standing at two public, Midwestern, Primarily White universities. These individuals were identified for participation in the study through the senior student affairs officers at their respective institutions and each were contacted initially through email to request participation in the study. Follow-up phone calls were then used to arrange for interviews, and interviews were conducted at 'safe spaces' that the individuals either identified or helped to identify, including closed conference rooms, a coffee shop, and an unused classroom.

The sample included 3 sophomores, 2 juniors, and 3 seniors, and these individuals were interviewed during the Spring 2020 academic semester. The interviews averaged 59 minutes in length, and each participant signed an approved informed consent form. The interview protocol was reviewed by non-participant African American men at the researchers institution, and the protocol was approved by the researcher's Institutional Review Board for human subject protection. 


\section{Results}

The first section of the interview protocol provided questions for the interview participants about their descriptions of personal experiences that led them to enroll and persist in higher education. The narratives from the eight students were reviewed with comments categorized by topic, and these topics were then validated by an external reviewer. The result was the identification of comments and topics that fell into three categories of themes: involvement related to academics and community, people make a difference, and personal motivation.

The involvement related to academics and community theme was comprised of multiple comments from all individuals. These comments included direct involvement with academic organizations in high school, college bridge programs, and their involvement with community organizations. For example, some students reported being involved in a TRIO program that provided them trips to and tours of different colleges during their summers. Other students discussed being involved with academic societies and clubs in school that exposed them to other students who talked about going to college and teachers who stressed the importance of their work and academic achievement as important to their future studies. And other students focused their comments on the things that they did and people they engaged with outside of school, particularly attending church. One student commented:

I have always been active in my church and would attend church events with my

mom. People in my church would always talk to be about going to college. They sponsored a special event at church when me and other students graduated from high school. Different people talked about continuing my education by going to college when they spoke during that program. Now, the same people ask about how I'm doing in school and that I make them proud that I will graduate with my degree. They make me feel good about what I'm doing. They keep me motivated to finish.

The theme of people making a difference included a broad swath of individuals that ranged from immediate and extended family members to school counselors, coaches, teachers. Aside from the intentional interactions that many of these individuals had that were directly focused on going to college, the participants also indicated that some unintentional conversations were also influential in their decision to go to college. These included next door neighbors who would ask about their plans after high school, part-time job supervisors who without prompting would encourage college, and even community members who would encourage college attendance without prompting. One student commented that a woman he did not know said to him in a store "you better go to college because if you stay around here you are just going to get in trouble."

The third broad theme dealt with a personal motivation to use education as a change agent in their lives. These included motivations being derived from negative scenarios in the student's home or neighborhood, illustrated by comments such as "some of the negative things that I see in my neighborhood made me want to leave home and go to a college far away from home. I just knew that I needed to be distant from home so I could have a different environment." Another student said "I got distracted in high school by people I felt like I 
outgrew. They kept making the same childish mistakes, like partying and making bad decisions. It made me want to go to college somewhere they weren't going to be."

The idea of motivation, however, was also seen in a personal desire to improve a life situation, to be seen in a better light by community members, to have respect, and even to think long term about the kind of life the students wanted to live. They also, though, saw continuing their education and eventually graduating as a tool to help their parents and families. A student said "my grandparents didn't graduate from college and they struggled to take care of me because they didn't have jobs that paid much money. I wanted to attend college because I didn't want to have to go through the same struggles that they had to go through." Another said "my mom doesn't make a lot of money and its hard for her to take care of my little sister and me. She did a lot for me and I just want to be able to take care of my momma and my sister."

The second section of the interview protocol focused on describing the role and perceived power of parental influence in the decision to enroll in higher education. The interview questions specifically focused on the roles of that these students' families played in developing perceptions, ideas, and attitudes about education as the students were growing up. The interviewed student comments were clustered into three themes: parents as resources, parental support, and parental expectations.

As resources, 6 of the 8 students interviewed indicated that their parents were strong, helpful resources in completing application materials and financial aid forms for college because the parents themselves had attended college. One student, for example, said "my parents could help me with applications because my dad recently completed a graduate degree and my mom has a nursing degree." Another said simply, "my mom had done everything before." For two students, however, the process was new, different, and difficult. One reported relying on a high school teacher to help him figure out how to apply to college and another had to find help from a neighbor.

All 8 of the students stressed in various comments that even if their parents and family members did not understand or completely agree with their choices and plans for the future, all felt that they had strong support from their families. Comments were short and direct, and stressed that the parents wanted success for their children. Such comments included "my dad really had my back," my mom "would give me the energy to keep going and not quit," and another said his dad would tell him to "keep his mind on the future" and that together they would "we can support each other and hold each other accountable."

The third theme identified in the comments was that of parental expectations of students to go to college and further their education. One father discouraged his son from enlisting in the military, as he had done, instead encouraging him to go away to college. A different student indicated that his mother had taken him to college classes when she was attending college through night school. These expectations were also manifest in comments like "my mom was really strict about school-work and taught me right from wrong," and that doing well in school was important. Three of these parents extended their thinking about going to college to giving back to their communities, churches, and families, and that they were expected to 
not only go to college and graduate, but to encourage others, such as their siblings and friends, to also go to college; they were expected to be role models.

\section{Discussion}

The stories of these 8 African American men reflect the ideas of Community Expectancy, that is, individuals incorporate their surroundings to make important, life changing decisions. In the case of these men, the community surrounding them was comprised of many different individuals, prominently their families and school communities, but also, importantly, organizations that carried a secondary function of socialization, namely, their church communities.

The result of communities expressing an expectation on an individual in the current study reinforced previous study by the research team (Tolliver, Kacirek, \& Miller, 2019), and a logical extension of these works would be to continue creating descriptions of interactions that might result in higher college going rates for African American men. Beyond continued descriptions of how coaches and teachers take a personal interest in a student, though, there must be some attempt to measure the meaningful impact of these interactions. Derden (2011) made one such attempt, focusing on small, rural communities and the variables that might impact postsecondary enrollment, but ultimately, his work was limited by an attempt to incorporate too many variables, resulting in inconclusive predictors of college attendance.

These findings, as an introduction to the emerging theory of Community Expectancy, do suggest that higher education institutions along with public agencies promoting greater African American participation in higher education need to think somewhat differently about their approaches to growing participation. Many programs currently exist to provide exposure to higher education to many under-represented populations, but they tend to be targeted at high school aged students, and targeted to the students themselves. Although such messaging is important, these descriptions suggest that parents and others are communicating expectations long before a junior or senior year in high school. Programs that target parents early in their child's life about educational opportunities and the power for continuing education past the age of 18 might well result in differing patterns of educational support. Colleges and universities might also be well served if they incorporated a variety of social agencies in their attempt to educate potential students about higher education access, and this could, for example, include messaging and collaborating with church leaders or others about how to mentor and support a student's interest in college.

These students' stories are important for multiple reasons, perhaps most importantly because they demonstrate the need to create meaningful, positive interactions with young adult men about what is expected of them. This can occur in many ways, both formally and informally, and suggest that mentoring activities can particularly serve an important element in creating opportunities for these men.

\section{References}

Bourdieu, P. (1986). The forms of capital. In J. C. Richardson (ed.), Handbook of Theory and Research for the Sociology of Education (pp. 241-258). New York, NY: Greenwood Press. 
Braddock, J. H., \& Hua, L. (2006). Determining the college destination of African American high school seniors: Does college athletic reputation matter? The Journal of Negro Education, 75(3), 532-545.

Brooms, D. R. (2018). Exploring Black male initiative programs: Potential and possibilities for supporting Black male success in college. The Journal of Negro Education, 87(1), 59-72. https://doi.org/10.7709/jnegroeducation.87.1.0059

Browne, A., \& Battle, J. (2018). Black family structure and educational outcomes: The role of household structure and intersectionality. Journal of African American Studies, 22(1), 77-93. https://doi.org/10.1007/s12111-018-9395-7

Calarco, J. M. (2011). "I need help!" Social class and children's help-seeking in elementary school. American Sociological Review, 76(6), 862-882. https://doi.org/10.1177/0003122411427177

Causey, S. T., Livingston, J., \& High, B. (2015). Family structure, racial socialization, perceived parental involvement, and social support as predictors of self-esteem in African American college students. Journal of Black Studies, 46(7), 655-677. https://doi.org/10.1177/0021934715592601

Cook, B. J., \& Córdova, D. I. (2007). Minorities in higher education twenty-second annual status report: 2007 supplement. Retrieved from http://health-equity.pitt.edu/996

Creswell, J. W., \& Poth, C. N. (2018). Qualitative inquiry and research design: Choosing among five approaches. Thousand Oaks, CA: Sage Publications.

DeBell, M. (2008). Children living without their fathers: Population estimates and indicators of educational well-being. Social Indicators Research, 87(3), 427-443. https://doi.org/10.1007/s11205-007-9149-8

Deggs, D., \& Miller, M. T. (2011A). Developing community expectations: The critical role of adult educators. Adult Learning, 22(3), 25-30. https://doi.org/10.1177/104515951102200304

Deggs, D., \& Miller, M. T. (2011B). The leadership of rural counties, their attributes, and indicators of educational attainment. e-Journal of Organizational Learning and Leadership, 9(1), 35-46.

Derden, M. W. (2011). Community expectations of college attendance and completion. Unpublished doctoral dissertation, University of Arkansas, Fayetteville, AR.

Derden, M. W., \& Miller, M. T. (2014). Predicting postsecondary attendance through cultural norming: A test of community expectancy. Critical Questions in Education, 5(2), 112-124.

Eckholm, E. (2006, March 20). Plight deepens for Black men, studies warn. New York Times. Retrieved online at http://www.nytimes.com/2006/03/20/us/plight-deepens-for-Black-men-studies-warn.html Elliott, W., \& Nam, I. (2012). Direct effects of assets and savings on the college progress of 
Black young adults. Educational Evaluation and Policy Analysis, 34(1), 89-108. https://doi.org/10.3102/0162373711425957

Erikson, E. H. (1950). Childhood and society. New York, NY: Norton.

Erikson, E. H. (1968). Identity, youth, and crisis. New York, NY: Norton.

Erikson, E. H. (1982). The life cycle completed: A review. New York, NY: Norton.

Ewert, S. (2010). Male and female pathways through four-year colleges: Disruption and sex stratification in higher education. American Educational Research Journal, 47(4), 744-773. https://doi.org/10.3102/0002831210374351

Ginther, D. K., \& Pollak, R. A. (2004). Family structure and children's educational outcomes: Blended families, stylized facts, and descriptive regressions. Demography, 41(4), 671-696. https://doi.org/10.1353/dem.2004.0031

Hines, E. M., Borders, L. D., Gonzalez, L. M., Villalba, J., \& Henderson, A. (2014). Parental involvement in college planning: Cultural considerations when working with African American families. Journal for Multicultural Education, 8(4), 249-260. https://doi.org/10.1108/JME-06-2014-0025

Kerpelman, J., Eryigit, S., \& Stephens, C. (2008). African American adolescents' future education orientation: Associations with self-efficacy, ethnic identity, and perceived parental support. Journal of Youth and Adolescence, 37(8), 997-1008. https://doi.org/10.1007/s10964-007-9201-7

Kim, J., Chatterjee, S., Young, J., \& Moon, U. J. (2017). The cost of access: Racial disparities in student loan burdens of young adults. College Student Journal, 51(1), 99-114.

Kim, E., \& Hargrove, D. T. (2013). Deficient or resilient: A critical review of Black male academic success and persistence in higher education. The Journal of Negro Education, 82(3), 300-311. https://doi.org/10.7709/jnegroeducation.82.3.0300

Madyun, N., \& Lee, M. (2010). Effects of religious involvement on parent-child communication regarding schooling: A study of Black youth in the United States. The Journal of Negro Education, 79(3), 295-307.

Merolla, D., \& Jackson, O. (2014). Understanding differences in college enrollment: Race, class and cultural capital. Race and Social Problems, 6(3), 280-292. https://doi.org/10.1007/s12552-014-9124-3

Miller, M. T., \& Tuttle, C. C. (2006). Rural community colleges role in community development: Unintentional outcomes of continuing and extended education activities.Catalyst: Journal of the National Council for Continuing Education and Training, 35(1), 7-12.

Moustakas, C. (1994). Phenomenological research methods. Thousand Oaks, CA: Sage Publications. https://doi.org/10.4135/9781412995658 
National Center for Education Statistics. (2014). The condition of education 2014. Washington, DC: Author.

Newton, V. A., \& Onésimo Sandoval, J. S. (2015). Educational expectations among African American suburban low to moderate income public high school students. Journal of African American Studies, 19(2), 135-156. https://doi.org/10.1007/s12111-015-9296-y

Price, G., \& Sheftall, W. (2015). The price elasticity of freshman enrollment demand at a historically Black college for males: Implications for the design of tuition and financial aid pricing schemes that maximize Black male college access. The Journal of Negro Education, 84(4), 578-592. https://doi.org/10.7709/jnegroeducation.84.4.0578

Purtell, K., \& McLoyd, V. (2013). Parents' participation in a work-based anti-poverty program can enhance their children's future orientation: Understanding pathways of influence. $\begin{array}{llll}\text { Journal of } \text { Youth and } & \text { 777-791. }\end{array}$ https://doi.org/10.1007/s10964-012-9802-7

Putnam, R. D. (2000). Bowling alone: The collapse and revival of American community. New York, NY: Simon \& Schuster. https://doi.org/10.1145/358916.361990

Robinson, K., \& Harris, A. L. (2013). Racial and social class differences in how parents respond to inadequate achievement: Consequences for children's future achievement. Social Science Quarterly, 94(5), 1346-1371. https://doi.org/10.1111/ssqu.12007

Scott, J. A., Taylor, K. J., \& Palmer, R. T. (2013). Challenges to success in higher education: An examination of educational challenges from the voices of college-bound Black males. The $\begin{array}{llll}\text { Journal of Negro } & \text { Education, } & \text { 288-299. }\end{array}$ https://doi.org/10.7709/jnegroeducation.82.3.0288

Snyder, T., \& Dillow, S. A. (2011). Postsecondary education. Digest of Education Statistics 2010, 281-283.

Sokol, J. T. (2009). Identity development through the lifetime: An examination of Eriksonian theory. Graduate Journal of Counseling Psychology, 1(2). Retrieved from https://epublications.marquette.edu/gjcp/vol1/iss2/14

Tekleselassie, A., Mallery, C., \& Choi, J. (2013). Unpacking the gender gap in postsecondary participation among African Americans and Caucasians, using hierarchical generalized linear modeling. The Journal of Negro Education, 82(2), 139-156. https://doi.org/10.7709/jnegroeducation.82.2.0139

Tolliver, D. V., III, Kacirek, K., \& Miller, M. T. (2019). The perceived family and parental influence of African American men who enroll in community colleges. Cross-CulturalCommunication, 15(1), 1-6.

Turner, E. A., Chandler, M., \& Heffer, R. W. (2009). The influence of parenting styles, achievement motivation, and self-efficacy on academic performance in college students. Journal of College Student Development, 50(3), 337-346. https://doi.org/10.1353/csd.0.0073 
van Manen, M. (2014). Phenomenology of practice: Meaning-giving methods in phenomenological research and writing. New York, NY: Routledge.

Venezia, A., \& Jaeger, L. (2013). Transitions from high school to college. Future of Children, 23(1), 117-36. https://doi.org/10.1353/foc.2013.0004

Warde, B. (2008). Staying the course: Narratives of African American males who have completed a baccalaureate degree. Journal of African American Studies, 12(1), 59-72. https://doi.org/10.1007/s12111-007-9031-4

Winkle-Wagner, R. (2010). Cultural capital: The promises and pitfalls in educational research. In K. Ward and L. E. Wolf-Wendel (Eds.), ASHE Higher Education Report. Hoboken, NJ: Wiley.

Yosso, T. J. (2005). Whose culture has capital? A critical race theory discussion of community cultural wealth. Race Ethnicity and Education, 8(1), 69-91. https://doi.org/10.1080/1361332052000341006

Zhang, Y., Haddad, E., Torres, B., \& Chen, C. (2011). The reciprocal relationship among parents expectations, adolescents' expectations, and adolescents' achievement: A two wave longitudinal analysis of the NELS data. Journal of Youth and Adolescence, 40(4), 479-489. https://doi.org/10.1007/s10964-010-9568-8

\section{Copyright Disclaimer}

Copyright for this article is retained by the author(s), with first publication rights granted to the journal.

This is an open-access article distributed under the terms and conditions of the Creative Commons Attribution license (http://creativecommons.org/licenses/by/4.0/). 